\title{
A interdisciplinaridade e a arte do malabarismo na formação de professores e professoras
}

\author{
Interdisciplinarity and the art of malabarism in teacher training \\ La interdisciplinaridad y el arte del malabarismo en la formación de \\ profesores y profesoras
}

ELIANA PÓVOAS PEREIRA ESTRELA BRITO

Resumo: O presente trabalho analisa dois Projetos de Cursos de Licenciaturas Interdisciplinares em Humanidades. Um deles, ofertado pela Universidade Federal do Maranhão (UFMA) e o outro, pela Universidade Federal do Pampa (UNIPAMPA). Busca compreender como a interdisciplinaridade é trabalhada nos Projetos Pedagógicos desses cursos e quais são as implicações para o perfil do profissional que se propõem formar. A análise identificou que a interdisciplinaridade seguiu abordagens diferentes em cada um dos projetos pedagógicos, mas, orientados por disposições legais comuns às licenciaturas, os dois cursos orientam-se pela lógica curricular disciplinar comprometendo a formação interdisciplinar a ser certificada aos futuros profissionais do magistério da Educação Básica.

Palavras-chave: Licenciaturas interdisciplinares; formação de professores; currículo.

Abstract: The present work analyzes two projects of Interdisciplinary Graduation Program in the Humanities, one of them offered by the Federal University of Maranhão (UFMA), and the other by the Federal University of Pampa (UNIPAMPA). It seeks to understand how interdisciplinarity is worked out in the Pedagogical Projects of the Courses and what are the implications for the formation of the professional profile that they propose to train. The analysis identified that interdisciplinarity followed different approaches in each of the Pedagogical Projects of the Courses but, guided by legal provisions common to the degrees, the two courses are guided by the disciplinary curricular logic committing the interdisciplinary training to be certified to the future professionals of the teaching profession of basic education.

Keywords: Interdisciplinary graduation programmes; teaching training; curriculum.

Resumen: El presente trabajo analiza dos Proyectos de Cursos de Profesorados Interdisciplinares en Humanidades. Uno de ellos, ofrecido por la Universidade Federal do Maranbão (UFMA), y otro, por la Universidade Federal do Pampa (UNIPAMPA). Se busca comprender cómo la interdisciplinaridad es trabajada en esos Proyectos Pedagógicos de los Cursos y cuáles son las implicaciones para la formación del perfil profesional a que se proponen formar. El análisis 
identificó que la interdisciplinaridad siguió abordajes diferentes en cada uno de los Proyectos Pedagógicos de los Cursos, sin embargo, orientados por disposiciones legales comunes a los profesorados, los dos cursos se orientan por la lógica curricular disciplinar comprometiendo la formación interdisciplinar a ser certificada a los futuros profesionales del magisterio de la educación básica.

Palabras clave: Profesorados interdisciplinares; formación de profesores; currículo.

\section{INTRODUÇÃO}

O Ministro da Educação, Aloizio Mercadante, em discurso proferido em 28 de março de $2016^{1}$, anunciou a criação de 105 mil vagas para professores e professoras da rede pública, afirmando que: "se nós quisermos ter qualidade na educação, nós teremos que resolver a formação do professor. Não há outro caminho. Eu diria que é o ponto mais estratégico para melhorar a educação no Brasil". A proposta do atual Ministro da Educação segue a lógica historicamente constituída pelas políticas educacionais a serviço da Educação Básica, que estabelecem correlações lineares e diretas entre as dificuldades apresentadas por esse nível de ensino e as supostas deficiências dos profissionais que nela atuam. E o remédio recomendado pelas políticas oficiais tem sido materializado por um vigoroso conjunto de proposições normativas que objetivam promover o melhoramento da Educação Básica a partir de intervenções na formação docente.

Embora, essas relações de forças entre formação de professores/as e demandas sociais, políticas, culturais e econômicas possam remeter à criação das Escolas Normais no século XIX, é possível afirmar que houve um acirramento dessas proposições, em especial a partir da Lei 9494/96 e incorporações posteriores. Tomando aqui a Lei de Diretrizes e Bases da Educação Nacional (LDB) como marco inicial, podemos dizer que atravessamos esses últimos vinte anos buscando, a partir de diferentes abordagens teóricas e de diversos enfoques metodológicos, resolver a velha dicotomia constituída pelo par teoria e prática enquanto peças centrais para a formulação das políticas de formação de professores e professoras.

Nessa direção, após a promulgação da Lei 9394/96, de Diretrizes e Bases, um conjunto de orientações normativas foi colocado à disposição dos professores em consonância com as modificações que concomitantemente eram previstas para a educação básica. Disseminando um discurso que atribui a disciplinarização dos conhecimentos o fracasso e o descompasso entre os processos de escolarização e as licenciaturas, as Diretrizes Curriculares Nacionais (CNE/CP 009/2001)

\footnotetext{
1 Discurso proferido em 28 de março de 2016. Disponível em: http:/ / portal.mec.gov.br/component/ content $/$ index.php?option $=$ com_content\&view $=$ article\&id $=35121$ :universidade-do-professor-oferecera-105mil-vagas-para-que-docentes-completem-formacao\&catid=211\&Itemid=86. Acesso em: 29/03/16.
} 
(BRASIL, 2001) pulverizaram um discurso em que a interdisciplinaridade, atrelada à noção de competência e de contextualização seria uma espécie de fórmula mágica para a solução dos problemas enfrentados na Educação Básica e na formação dos profissionais que nela atuam. Lê-se nas DCNs:

\begin{abstract}
A maioria das capacidades que se pretende que os alunos da educação infantil, do ensino fundamental e do médio desenvolvem, atravessa as tradicionais fronteiras disciplinares e exige um trabalho integrado de diferentes professores. Na perspectiva da simetria invertida, isso reforça a necessidade de que a matriz curricular da formação do professor contemple estudos e atividades interdisciplinares (BRASIL, 2001, p. 54).
\end{abstract}

Guiadas por essas diretrizes, as instituições de Ensino Superior, responsáveis pela formação de professores, vêm apostando em cursos de licenciaturas que atendam às qualificações normativas como possibilidade de contribuírem para a qualificação da Educação Básica. Entre essas iniciativas, as Licenciaturas Interdisciplinares $^{2}$ (LIs), cuja a emergência se deu como uma das contrapartidas da adesão das universidades públicas às metas propostas pelo Programa de Apoio a Planos de Reestruturação e Expansão das Universidades Federais (REUNI) ${ }^{3}$.

Uma das universidades que ganhou destaque nacional no REUNI foi a Universidade Federal da Bahia (UFBA). Essa instituição apresentou uma proposta de restruturação dos cursos de graduação por meio da criação dos Bacharelados Interdisciplinares (BI), em total consonância com as diretrizes gerais do REUNI ${ }^{4}$, "dotando a UFBA de uma nova estrutura de cursos de graduação, interdisciplinar, flexível, abrangente e articulada à pós-graduação, posicionando-se como a primeira universidade brasileira a ter uma estrutura curricular compatível com regime modulares de formação de ciclos" (UFBA, 2008, p.5).

Os cursos de Bacharelados Interdisciplinares são definidos como programas de formação em nível de graduação de natureza geral, que conduzem à

2 Aqui, cabe uma ressalva: enquanto os cursos de Bacharelados Interdisciplinares tiveram, pelo Parecer CNE/CES n 266/2011, seus referenciais orientadores homologados, os cursos de licenciaturas interdisciplinares por não terem sido devidamente subsidiados pelo "Grupo de Trabalho dos Bacharelados e Licenciaturas Interdisciplinares”, constituído pela SESu/MEC, Portaria n 383/2010, não possuem sustentação legal neste Parecer.

3 O Programa REUNI foi instituído pelo Decreto $\mathrm{n}^{\circ}$ 6.096, de 24 de abril de 2007, enquanto uma das ações integrantes do Plano de Desenvolvimento da Educação (PDE) atribuindo à Educação Superior um papel estratégico para o desenvolvimento econômico e social. O REUNI, como já amplamente divulgado, teve como mote estruturador, a expansão e a interiorização da Educação Superior pública, a partir da reestruturação das instituições federais de ensino superior (IFES), como uma das condições de adesão ao programa.

4 A Universidade Federal do $\mathrm{ABC}$ (UFABC), que já apostava na formação interdisciplinar da graduação (bacharelados), foi criada, em 2005, já no âmbito do REUNI e seguindo as diretrizes previstas pelo Programa. 
diplomação, a partir de grandes áreas do conhecimento (Linguagens; Humanidades; Saúde; Ciência e suas tecnologias). Esses cursos, com terminalidades próprias, devem desenvolver competências, habilidades e conhecimentos gerais congruentes e alinhadas às necessidades do mundo do trabalho apresentadas pela Organização Internacional do Trabalho (OIT), do Sistema das Nações Unidas, na Conferência Mundial de Educação Superior da UNESCO, realizada em Paris no ano de 1998 (BRASIL,2011).

Os "Referenciais orientadores para os Bacharelados Interdisciplinares e Similares das Universidades Federais" (BRASIL, 2010) trazem como princípios norteadores: formação acadêmica baseada na interdisciplinaridade, metodologias ativas, alta flexibilização curricular, foco nas dinâmicas de inovação científica, tecnológica, competências e habilidades, estímulo à iniciativa individual, à capacidade de pensamento crítico, à autonomia intelectual, ao espírito inventivo, inovador e empreendedor, valorização do trabalho em equipe, entre outros.

Em consonância com esses princípios e suas promessas inovadoras, 15 universidades federais iniciaram, a partir de 2006, a oferta de cursos interdisciplinares. Entre esses cursos, são criadas as licenciaturas interdisciplinares, cuja emergência se dá a partir do atendimento às metas e estratégias colocadas pelo REUNI para as universidades. Por efeito, trata-se de uma invenção políticopedagógica que atende às demandas de uma reforma universitária pautada pelo reordenamento das relações sociais, culturais e econômicas nas sociedades contemporâneas.

Disseminando um discurso desqualificador da Educação Superior pública brasileira, o REUNI centrou suas críticas na organização curricular dos cursos de graduação, descritos como fragmentados, desarticulados e defasados em relação às demandas contemporâneas. Nessa esteira discursiva, postulou a favor da necessidade de que mudanças curriculares profundas e urgentes ocorressem, pois "a manutenção da atual estrutura curricular de formação profissional e acadêmica, ao reforçar as lógicas da precocidade profissional e da compartimentação do saber, coloca o país em risco de isolamento nas esferas científica, tecnológica e intelectual de um mundo cada dia mais globalizado e inter-relacionado" (BRASIL,2007a, p.10).

Avançando na agenda do texto, uma brevíssima inserção histórica vai apontar a emergência da noção de interdisciplinaridade nos textos acadêmicos, políticos e empresariais, a partir da década de 1960, tendo no relatório do Centro para a Pesquisa e Inovação do Ensino (CERI), filiado à Organização para Cooperação e Desenvolvimento Econômico (OCDE), seu marco inaugural. Seguindo as orientações dos estudos realizados por Hilton Japiassu (1976), referência pioneira sobre o tema da interdisciplinaridade no Brasil, foi a partir do Seminário 
sobre interdisciplinaridade e transdisciplinaridade e na posterior realização do "Seminário internacional sobre pluridisciplinaridade e interdisciplinaridade nas universidades", ambos realizados em 1970 pelo CERI/OCDE e pelo Ministério da Educação Francês, que as noções de pluri(disciplinaridade), inter(disciplinaridade) e trans(disciplinaridade), sob a ótica da reflexão epistemológica, iniciaram suas trajetórias de problematizações.

As demandas políticas, sociais, culturais pelo estabelecimento de novas bases conceituais que contribuíssem para romper com as características do modelo disciplinar, suas fragmentações e especializações por campos de conhecimentos se dão em um momento histórico marcado tanto pelas reivindicações estudantis frente às formas de organização e estruturação do ensino, em especial, na França, quanto pelo declínio do modelo taylorista/fordista dos modos de produção capitalista das décadas de 60 e 70, do século passado. Em poucas palavras, a interdisciplinaridade, surge pelo tensionamento de forças produzidas pelo mundo do trabalho a partir da reestruturação do capital e pelos movimentos estudantis na França, insatisfeitos com um tipo de sistema de ensino que se mostrava precário ao mundo acadêmico.

As interações entre o mundo do trabalho e o da educação, foram discutidas, entre outros autores, por Mueller; Bianchetti, Jantsch (2011), quando tomaram como argumento central de sua problematização a tese de que a interdisciplinaridade, a partir do início da década de 1970, tem sido um conceito que vem sendo apropriado pelo mundo da produção, objetivando (em nível teórico e prático), "demandar da escola/universidade, um egresso cada vez mais adequado às características exigidas pelo atual mercado: flexível, maleável, adaptável, ajustável, disponível para as constantes mudanças do modo de produção vigente" (p. 175). Segundo os autores, a pergunta que deve ser feita deveria enfrentar, numa perspectiva histórica crítica, o seguinte paradoxo:

\footnotetext{
Durante anos a escola e a universidade formaram especialistas porque o mercado funcionava sob a égide da divisão técnica e social do trabalho, característica do paradigma taylorista-fordista, exigindo assim trabalhadores parcialmente preparados. Vamos açodadamente, nos empenhar em formar o generalista, o suposto trabalhador "interdisciplinar" porque esta é mais uma demanda do mercado? (Idem, p.188).
}

Nesta direção, embora ainda não tenhamos Diretrizes Curriculares que tratem, de forma específica, a formação de professores numa perspectiva nomeadamente interdisciplinar - Licenciaturas Interdisciplinares - sabemos que, desde o Programa REUNI, algumas universidades vêm apostando nessa modalidade de formação para professores, em consonância, com os textos políticos que normatizam e orientam a educação básica e a formação inicial e 
continuada de seus profissionais. Se aceitarmos as provocações de Mueller, Bianchetti, Jantsch (2011), podemos questionar: A proposta de formação interdisciplinar do professor e da professora é mais uma produção acadêmica ajustada às exigências das reestruturações sofridas pelo mundo do trabalho? A que identidade profissional essas licenciaturas remetem?

Para buscar responder a essas questões, analiso dois Projetos de Cursos de Licenciaturas Interdisciplinares em Humanidades, oferecidos por duas instituições federais de ensino: Universidade Federal do Maranhão (UFMA) e Universidade Federal do Pampa (UNIPAMPA), tendo como ferramenta operacional para a análise a noção de interdisciplinaridade presente nos documentos oficiais que orientam os cursos de formação de professores e na literatura especializada na área. A escolha desses dois projetos pedagógicos de curso (PPCs) se deve, muito especialmente, ao fato de terem sido eles os primeiros cursos de licenciaturas interdisciplinares ofertados no Brasil.

\section{A INTERDISCIPLINARIDADE NOS PROJETOS PEDAGÓGICOS DOS CURSOS ANALISADOS}

Os dois projetos pedagógicos de curso (PPCs) analisados guardam algumas características comuns: ambos foram criados em decorrência do REUNI. De igual forma, os PPCs reconhecem o caráter político que os cursos possuem na perspectiva da interiorização e expansão da formação de professores que atendam às demandas locais e regionais, em consonância com as proposições presentes nas disposições legais que os orientam. Cabe ressaltar que como foram licenciaturas criadas antes da recente publicação das Novas Diretrizes Curriculares Nacionais para a Formação Inicial e Continuada dos Profissionais do Magistério da Educação Básica (PARECER CNE/CP No:2/2015), esses PPCs, seguem, em termos de diretrizes para a formação de professores, as orientações previstas no Parecer CNE/CP 09/2001 (BRASIL, 2001) e na Resolução CNE/CP 1, de 18 de fevereiro de 2002 (BRASIL, 2002), que instituem as Diretrizes Curriculares Nacionais para a Formação de Professores da Educação Básica, em nível superior, curso de licenciatura de graduação plena. 


\section{O PROJETO PEDAGÓGICO DO CURSO DE LICENCIATURA INTERDISCIPLINAR EM CIÊNCIAS HUMANAS/HISTÓRIA DA UNIVERSIDADE FEDERAL DO MARANHÃO (UFMA)}

A proposta se apresenta como um curso de formação interdisciplinar na área de Ciências Humanas (História, Geografia, Filosofia e Sociologia), preparando professores para atuarem nos anos finais do Ensino Fundamental e de História para atuar no Ensino Médio. O PPC analisado é a reescrita de uma primeira proposta, apresentada pela UFMA ao REUNI, a qual era orientada por matriz de competências. Essa proposta foi criticada pelos docentes, na medida em que, "criava grandes dificuldades para sua efetivação, tendo em vista não haver conteúdo ou componente curricular, apenas indicativo de competências e temas" (UFMA, 2013, p. 8.).

A proposta reescrita, na perspectiva da interdisciplinaridade, inscrevese na "vertente da complexidade" (PORTO; ALMEIDA, 2002) e baseia seus pressupostos a em uma crítica epistemológica à ciência contemporânea, argumentando, a partir da incorporação da temática da complexidade, a favor da integração disciplinar como mote de reestruturação do conhecimento. O curso mantém uma estrutura curricular disciplinar, "sem perder de vista a interdisciplinaridade", segue o regime acadêmico (disciplinar) adotado pela UFMA e "se constitui numa formação interdisciplinar conexa a uma formação específica, fortalecendo o perfil profissional do egresso do curso”. De acordo com o PPC: "Este é um projeto interdisciplinar pela busca de um pensamento que reconhece a complexidade como conceito e que, ao reconhecer o todo em cada parte, identifica a incompletude de cada uma e a necessária complementaridade entre todas" (UFMA,2013. p. 9).

O referencial teórico utilizado no PPC traz um cuidadoso esforço de urdidura como forma de situar a interdisciplinaridade como conceito cuja sustentação se dá "pelo pensamento complexo que possibilita repensar a prática pedagógica a partir da seguinte questão posta pela teoria da complexidade: quais são as possibilidades ainda não exploradas de complexidade?" (Morin, 1999, p. 309 apud UFMA, 2013, p.14). Conhecedores das dificuldades e dos desafios para dar materialidade a um currículo estruturado por um conjunto de disciplinas agrupadas em Núcleos (Núcleo da formação básica; Núcleo da formação livre, Núcleo da formação específica, Núcleo da formação pedagógica e Práticas pedagógicas) encadeados, anualmente, por Eixos Articuladores como espaços de interações disciplinares e interdisciplinares, os autores reconhecem que: 
Por mais que se ouse um projeto interdisciplinar, precisamos reconhecer que o prefixo mantém a relação entre as diferentes áreas e são estas que sustentam essa relação de complementaridade. (...). Dizemos isso porque acreditamos que, enquanto o foco do ensino for o conteúdo, estará posta a impossibilidade do olhar complexo e interdisciplinar. Acreditamos que esse jeito que se diz novo, mas que a filosofia desde antes orienta a ser, é uma prática que só será alcançada no momento em que o objeto for deslocado do centro da pesquisa e o objeto de pesquisa for posto no seu devido lugar: no eixo do ensino (UFMA, 2013, p. 14).

Os autores do Projeto Pedagógico do Curso buscam, nas orientações das Diretrizes Curriculares Nacionais, criar espaços curriculares que favoreçam as articulações interdisciplinares e exemplificam, a partir das prováveis associações entre os núcleos (específico, complementar e de opções livres disciplinas optativas), a possibilidade de, ao ampliarem os conteúdos específicos, possibilitarem "ao aluno aprofundamento consequente do que ele pode escolher em outra área dentro do currículo com a qual ele poderá fazer as articulações necessárias" (UFMA, 2013, p. 15). Aqui, importa sublinhar que a complexidade dos fenômenos vai exigir do professor uma postura inter ou transdisciplinar para que possa ser conhecida em toda a dimensão conectiva. Ou seja, o desafio da proposta fica por conta de trabalhar entre a intenção - claramente colocada no PPC - e a ação, as incertezas, dúvidas e decisões a serem enfrentadas pelo agir individual e/ou coletivo dos docentes. Assim, a interdisciplinaridade enquanto orientadora da prática pedagógica corre o risco de fracassar ou de sofrer desvios ou distorções de sentidos.

Considerando-se que, para Morin (2005), o método é a caminhada, as certezas e as incertezas que dela emergem, seus fluxos e refluxos, a metáfora que fica para a interdisciplinaridade trabalhada no PPC de Licenciatura Interdisciplinar em Ciências Humanas - História, ofertado pela UFMA, remete à metáfora do viajante, de Antônio Machado, quando diz que "viajante, não existe caminho, o caminho nasce de tua caminhada". Em poucas palavras, a pergunta que fica é: a interdisciplinaridade confinada às vontades pessoais ou de grupos poderá vir a ser uma estratégia de ensino-aprendizagem que favoreça a compreensão das realidades sociais, seus acontecimentos, suas diversidades culturais e diferenças étnicoraciais, sexuais e de gênero? Não seria ela - a interdisciplinaridade - prisioneira das compreensões, sentidos e significações das singularidades constitutivas dos sujeitos? 


\title{
O PROJETO PEDAGÓGICO DO CURSO DE LICENCIATURA EM CIÊNCIAS HUMANAS DA UNIVERSIDADE FEDERAL DO PAMPA - UNIPAMPA
}

A proposta é apresentada como um projeto pedagógico de curso baseado "em uma perspectiva interdisciplinar, presencial, pela qual os futuros profissionais poderão qualificar-se a partir da interação com outras ferramentas e conhecimentos oferecidos nos cursos já implantados (...) (UNIPAMPA, 2011, p. 5). O curso, para além da promoção da formação inicial, propõe-se servir de complementação à formação de pesquisadores, pesquisadoras, professores, professoras e profissionais na área das Ciências Humanas: história, sociologia, filosofia e geografia. E pode, também, servir como primeiro ciclo de segunda licenciatura. Nesse caso, o curso assume um "caráter disciplinar, em História, Geografia, Sociologia e Filosofia, visando às dimensões da formação continuada, da complementação de estudos e para uma atuação mais qualificada no Ensino Médio" (UNIPAMPA, 2011, p. 5)

De acordo com o PPC:

\begin{abstract}
O princípio norteador dessa formação é a competência como concepção nuclear na orientação do curso. Ou seja, a competência como orientadora tanto da proposta pedagógica, especialmente do currículo e da avaliação, quanto da organização institucional e da gestão da escola de formação e a coerência entre a formação oferecida e a prática esperada do professor, tendo em vista a simetria invertida, a aprendizagem como processo de construção de conhecimentos, habilidades e valores (UNIPAMPA, 2011, p.31. Sublinhado no texto).
\end{abstract}

Não é objetivo deste artigo problematizar a noção de competência enquanto princípio norteador dos currículos dos cursos de licenciaturas. Muito menos, reproduzir o que tem sido amplamente debatido e divulgado em publicações da área educacional, em especial, os estudos preocupados em analisar as Diretrizes Curriculares Nacionais e suas implicações para a formação de professores. Meu interesse aqui é bem específico. Trata-se de compreender como a interdisciplinaridade encontra-se prevista no PPC e quais suas implicações para a formação do professor interdisciplinar que se propõe formar.

Isso posto, o currículo do curso se encontra organizado tendo em vista três eixos articuladores: o "eixo da verticalidade", agrupa as disciplinas específicas das cinco áreas a que a licenciatura prevê habilitar: Educação, Humanidades, Filosofia, História, Sociologia e Geografia. O "eixo da horizontalidade" é voltado à integração entre conteúdos e métodos das disciplinas em todas as fases (semestres). A flexibilização se caracteriza pela possibilidade de que, após cursar os conteúdos comuns a todas as áreas que compõem o currículo, o licenciando 
possa, através da oferta de disciplinas obrigatório-eletivas e de atividades complementares individualizadas, escolher percursos acadêmico-profissionais singulares (UNIPAMPA/PPC, 2011).

Esses eixos não são fáceis de visualizar no desenho curricular do curso. E, mais delicado ainda, é identificar suas potencialidades integradoras. A arquitetura curricular é apresentada em formato de "grade disciplinar", sequencial e hierarquizada. Prevê, a partir do quarto semestre, disciplinas eletivas (150 horas), distribuídas semestralmente até o fim do curso. $\mathrm{O}$ trabalho de conclusão de curso (TCC) - monografia - tem seu desenvolvimento curricular no sexto e no oitavo semestres (TCC I e TCC II). De natureza "processual e acumulativa", essas disciplinas

Além de instituírem exercício de prática de pesquisa com complexidade superior
àquelas desenvolvidas no decorrer do curso, atividade efetiva, pois, de articulação
entre ensino e pesquisa, é o momento de aplicação e aprofundamento do conjunto
de conhecimentos construídos ao longo da graduação (UNIPAMPA, 2011 p. 64).

Ao caracterizar o TCC como disciplinas que pressupõem o desenvolvimento de pesquisa, supõe-se que seja nesses espaços/tempos curriculares que a interdisciplinaridade possa ocorrer. Como o desenvolvimento das disciplinas ${ }^{5}$ - e a própria integração entre elas - encontra-se orientada pelas competências a serem adquiridas pelo futuro professor, é possível pensar que as potencialidades atribuídas à interdisciplinaridade possam ficar reduzidas a uma mera instrumentalização técnica.

É preciso dizer, no entanto, que as dificuldades encontradas nesse PPC referentes à interdisciplinaridade podem ser provenientes do Parecer CNE/CP 09/2001 (BRASIL, 2001) e da Resolução CNE/CP 1, de 2002 (BRASIL,2002b) que instituíam as DCNs para a formação de professores. Nesses documentos, as orientações em relação à interdisciplinaridade são ambíguas e multifacetadas. Ao mesmo tempo em que apresentam a interdisciplinaridade como um dos princípios articuladores, propõem, também, um currículo por competências. Talvez seja esse um dos motivos pelos quais o PPC, em consonância com estas diretrizes, vai propor: "uma aproximação à interdisciplinaridade que, antes de garantir a associação temática entre diferentes áreas do conhecimento, deve possibilitar a unidade em termos de prática docente". (UNIPAMPA, 2011, p. 39). Ou seja, a lógica que organiza o currículo permanece numa perspectiva disciplinar, sendo

5 Além destes espaços/tempos, o PPC atribui ao "eixo da horizontalidade" a integração entre conteúdos e métodos das disciplinas ministradas a cada semestre. No entanto, o texto não traz elementos que possibilitem identificar como esses movimentos ocorrem e quais suas implicações na formação dos estudantes. 
que, as competências, em conformidade com o perfil do profissional a ser formado, passam a atuar com efeitos de regulação sobre as disciplinas e suas possibilidades de integração.

Sobre a possibilidade de a interdisciplinaridade possibilitar alguma forma de unidade integradora, Etges (1993, p. 21) vai argumentar que:

A interdisciplinaridade, enquanto princípio mediador entre as diferentes disciplinas, não poderá jamais ser elemento de redução a um denominador comum, mas elemento teórico-metodológico da diferença c da criatividade. A interdisciplinaridade é o princípio da máxima exploração das potencialidades de cada ciência, da compreensão dos seus limites, mas, acima de tudo, é o princípio da diversidade e da criatividade.

A proposta trabalha definições de interdisciplinaridade, extraídas dos estudos de Mello (2009), Lück (1995), Fazenda (1994) como respaldo teóricometodológico à proposta pedagógica. Estas conceituações, hegemônicas no campo da educação brasileira, aproximam-se do que Jantsch e Bianchetti (1995), vão denominar "filosofia do sujeito". Segundo estes autores, essa abordagem privilegia a ação do sujeito sobre o conhecimento, "de modo a tornar o sujeito um absoluto na construção do conhecimento e do pensamento." (JANTSCH; BIANCHETTTI, 1995, p. 23). Destaca-se, nessa perspectiva, um certo voluntarismo do sujeito e a interdisciplinaridade assume o caráter de atitude. Exemplar disso é a citação de Fazenda (1994, p. 92) presente no PPC. Reproduzo abaixo:

Entendemos por atitude interdisciplinar uma atitude diante de alternativas para conhecer mais e melhor; atitude de espera ante os atos consumados, atitude de reciprocidade que impele à troca, que impele ao diálogo - ao diálogo com pares idênticos, com pares anônimos ou consigo mesmo - atitude de humildade diante da limitação do próprio saber, atitude de perplexidade ante a possibilidade de desvendar novos saberes, atitude de desafio - desafio perante o novo, desafio em redimensionar o velho - atitude de envolvimento e comprometimento com os projetos e com as pessoas neles envolvidas, atitude, pois, de compromisso em construir sempre da melhor forma possível, atitude de responsabilidade, mas, sobretudo, de alegria, de revelação, de encontro, de vida (UNIPAMPA, 2011, p. 14).

Jantsch e Bianchetti (1995), entendem que o processo de fragmentação do conhecimento manteve conexões diretas com o processo de fragmentação do trabalho que caracterizou o taylorismo (divisão do trabalho) e o fordismo (produção em série), sendo que a reestruturação na organização do trabalho, agora aos moldes do toyotismo, encontra-se diretamente relacionada às mudanças no sistema de produção capitalista. Nesse sentido, a formação profissional conveniente ao mundo do trabalho já não corresponde ao modelo de educação disciplinar de 
antes. Agora, um conjunto de novas "competências" e "habilidades" se fazem necessárias ao novo tipo de capitalismo. Entre elas: flexibilidade, competência, trabalho em equipe, autonomia, interdisciplinaridade.

No que pese minha concordância às críticas feitas à vertente humanista e sua aposta no sujeito do iluminismo para dar conta da interdisciplinaridade, o fato é que não podemos esquecer que "as luzes que descobriram as liberdades inventaram também as disciplinas" (FOUCAULT, 1988, p.123). A "disciplina é um princípio de controle de produção de discurso" (FOUCAULT, 1994, p.38) e, também, uma tecnologia política que se exerce com poderes de governar o espaço, o tempo, a distribuição do conhecimento, de forma piramidal. Essa disciplinarização - presente na escola, na universidade e em outras instituições de sequestro - possibilita o controle do ensino-aprendizagem e dos sujeitos envolvidos em seus processos (professores e estudantes).

Dito isso, entendo que a lógica que correlaciona interdisciplinaridade com reestruturação capitalista é importante pelo valor atribuído à materialidade histórica e suas condições de existência. No entanto, torna-se simplista, ao meu ver, se analisada meramente pelo viés da reprodução: escola/mundo do trabalho. É preciso admitir que as ciências modernas, suas compartimentações, especializações e encastelamentos não dão conta de responder às questões colocadas em nossa contemporaneidade. E essas questões não dizem respeito unicamente à reestruturação produtiva e seus determinantes. São relações constituidoras das dimensões culturais, políticas, éticas e estéticas.

É bem verdade também que os esforços teóricos que vêm sendo realizados na tentativa de tornar a noção de interdisciplinaridade uma ferramenta operacional que potencialize as aproximações entre os diferentes campos de saber vêm-se deparando com as dificuldades impostas pela própria racionalidade que preside os desenhos curriculares dos cursos de formação de professores no Brasil. Ao partirem do entendimento de que a soma das partes forma e fundamenta o todo, a organização curricular disciplinar remete à difícil problemática de se pensar como fazer a interdisciplinaridade acontecer nas práticas curriculares dos cursos de formação. Essa árdua tarefa, pouco problematizada nos textos oficiais e na própria literatura da área, vem produzindo arranjos curriculares que buscam o "como fazer" um curso interdisciplinar em detrimento dos motivos pelos quais somos convocados a fazer interdisciplinaridade como solução para a qualificação da formação docente. Mas eu questiono: nós, formadores de futuros professores, sabemos como fazer a interdisciplinaridade acontecer? Não seria necessário discutirmos as (im)possibilidades de práticas interdisciplinares inscritas em um solo epistêmico marcadamente disciplinar? Não seria necessário redesenhar as arquiteturas curriculares a partir de um outro patamar epistemológico? 


\section{LICENCIATURAS INTERDISCIPLINARES: METÁFORAS E SIMULACROS}

Problematizando a noção de interdisciplinaridade, Olga Pombo (2006), chama-nos a atenção para a complexidade que caracteriza a transformação epistemológica em curso. Argumenta que: "quanto mais fina é a análise, maior a complexidade que se abre à nossa frente. E, portanto, que o todo não é a soma das partes. Esta é, penso eu, uma das chaves fundamentais para o entendimento desta questão" (p. 10).

Aceitando o argumento de que a interdisciplinaridade precisa ser pensada a partir das transformações epistemológicas que caracterizam as sociedades atuais, defendo a tese de que ela necessita ultrapassar a racionalidade imposta pelas ciências modernas que têm na metáfora da árvore sua lógica de estruturação dos conhecimentos: tronco comum e galhos que se bifurcam, mas que não se comunicam entre si. A metáfora arbórea - presente nos dispositivos legais e em grande parte da literatura educacional - contribui muito mais para o aumento da profusão conceitual confusa, ruidosa e, por vezes, contraditória da noção de interdisciplinaridade do que para o seu fortalecimento.

A tentativa de seguir os preceitos legais e atender à urgência da necessidade de formar professores que respondam às demandas contemporâneas da educação básica, se constituem em fatores que favorecem simulacros e malabarismos na construção de Projetos Pedagógicos dos Cursos de Licenciaturas Interdisciplinares. Mesmo diante do esforço de urdidura para esculpir um perfil profissional liberto das "grades", o desenho curricular não ultrapassa os aprisionamentos impostos pelos quadriculamentos, suas territorializações e hierarquizações.

Assim, por mais que as formações interdisciplinares reivindiquem para si a promoção de aprendizagens significativas, de descobertas de novos saberes e fazeres, enquanto elas se mantiverem subordinadas aos limites fixados pelas disciplinas, dificilmente poderão criar tempos/espaços potencializadores de devires. Como não existem linhas de fuga que deem abertura à multiplicidade de conexões, aproximações, rupturas e rearranjos entre os conhecimentos, os currículos se mantém disciplinares e disciplinadores de uma formação profissional cuja identidade docente encontra-se esfacelada.

Dessa forma, as saídas encontradas pelos Projetos Políticos dos Cursos analisados se deram pela manutenção e reafirmação de uma matriz disciplinar que comportasse em suas quadrículas os conhecimentos constitutivos da grande área de humanidades - sociologia, filosofia, história e geografia - como possibilidade de anunciarem um perfil profissional interdisciplinar. As questões que daí decorrem ficam por conta de saber até que ponto essas licenciaturas, 
autodenominadas interdisciplinares, vão ao encontro da qualificação da Educação Básica e até que ponto elas apenas servem para dar uma solução desqualificada para as históricas lacunas deixadas pelas ausências de profissionais habilitados para o exercício do magistério nessa etapa da educação. Como se afirmarão as identidades profissionais desses professores polivalentes frente ao coletivo de docentes habilitados por campos específicos de conhecimento? Caberá a eles e a elas o lugar de malabaristas frente às divisões curriculares presentes no trabalho escolar?

\section{REFERÊNCIAS}

BRASIL. MEC/CNE. Parecer $\mathrm{n}^{\circ}$ 266, de 06 de julho de 2011. Diário Oficial da União. Brasília (DF), 14 out. 2011, seç.1, p. 16. Disponível em: <file:///C:/ Users/Usu\%C3\%A1 rio/Downloads/pces266_11.pdf>. Acesso em: 26 fev. 2016.

BRASIL.MEC/SESu. Diretrizes Gerais do Programa de Apoio a Planos de Reestruturação e Expansão das Universidades Federais - REUNI. Brasília, DF: MEC: SESu, 2007b. Disponível em: <http://portal.mec.gov.br/sesu/ arquivos/pdf/ diretrizesreuni.pdf>. Acesso em: 26 jan. 2016.

BRASIL. Decreto $n^{\circ}$ 6.096, de 24 de abril de 2007. REUNI. Diário Oficial da União. Brasília (DF), 25 abr. 2007. Disponível em: <http:/ /www.planalto.gov.br/ ccivil_03/_Ato2007-2010/2007/Decreto/D6096.htm>. Acesso em: 20 jul. 2015.

BRASIL/CNE. Parecer CNE-CP n ${ }^{\circ}$ 09, de 08 de maio de 2001. Institui Diretrizes Curriculares Nacionais para a Formação de Professores da Educação Básica, em nível superior, curso de licenciatura, de graduação plena Brasília: Conselho Nacional de Educação, 2001. Disponível em: http://portal.mec.gov.br/cne/ arquivos/pdf/009.pdf. Acessado em: 18 de julho de 2014.

BRASIL. Lei n ${ }^{\circ}$ 9394/96. Diário Oficial da União. Brasília, 20 de dezembro de 1996. Disponível em: < http://legislacao.planalto.gov.br/legislacao>. Acesso em: 13 jul. 2014.

BRASIL/CNE. Resolução CNE/CP 2/2002. Diário Oficial da União, Brasília, 4 mar. 2002a. Disponível em: <http://mec.gov.br>. Acesso em: 13 jul. 2014.

BRASIL/CNE. Resolução CNE/CP 1/2002. Diário Oficial da União, Brasília, 09 abr. 2002b. Disponível em: <http://mec.gov.br>. Acesso em: 13 jul.2014. 
BRASIL/SESu. Referenciais Orientadores para os Bacharelados Interdisciplinares e Similares. Brasília, DF: MEC/SESu, 2010. Documento elaborado pelo Grupo de Trabalho instituído pela Portaria SESu/MEC No. 383, de 12 de abril de 2010. Disponível em: < http:/ / www.ufabc.edu.br/images/ stories/comunicacao/bacharelado_interdisciplinares_referenciais-orientadores -novembro_2010 - brasilia.pdf>. Acesso em: 29 out. 2011.

BRASIL/Ministério da Educação. CNE. Parecer CNE-CP n ${ }^{\circ}$ 02, de 09 de junho de 2015. Institui Diretrizes Curriculares Nacionais para a Formação Inicial e Continuada dos Profissionais do Magistério da Educação Básica. Brasília: Conselho Nacional de Educação, 09 de junho de 2015.Disponível em: http://portal. mec.gov.br/index.php?option $=$ com_docman\&view $=$ download\&alias $=17719$ res-cne-cp-002-03072015\&category_slug=julho-2015-pdf\&Itemid=30192. Acessado em: 20 de julho de 2016.

ETGES, N. Ciência, interdisciplinaridade e educação. In: JANTSCH, A.; BIANCHETTI, L. (Org.). Interdisciplinaridade: para além da filosofia do sujeito. Petrópolis: Vozes, 1995. p. 51-84.

FAZENDA, I. A. Interdisciplinaridade: história, teoria e pesquisa. $4^{\mathrm{a}}$ edição. Campinas: Papirus, 1994.

FOUCAULT, M. A ordem do discurso. Edições Loyola, São Paulo, Brasil, 1994.

FOUCAULT, M. Vigiar e punir: nascimento da prisão. Petrópolis: Vozes, 1988.

JANTSCH, A.; BIANCHETTI, L. (Org.). Interdisciplinaridade: para além da filosofia do sujeito. Petrópolis: Vozes, 1995.

JAPIASSU, H. Interdisciplinaridade e patologia do saber. Rio de Janeiro: Imago, 1976.

LÜCK, H. Pedagogia interdisciplinar: fundamentos teórico-metodológicos. Petrópolis: Vozes, 1995.

MELO, A. I. S. C. de; ALMEIDA, G. Interdisciplinaridade: possibilidades e desafios para o trabalho profissional. In: Capacitação em Serviço Social e Política Social: o trabalho do assistente social e as políticas sociais, Módulo 
4: Brasília: NED/Cead - Universidade de Brasília,2000. pp.23-44 Brasília: UNB/CEAD, 2000. (V. 4).

MORIN E. O método 6: ética. Porto Alegre: Sulina; 2005.

MUELLER, R.; JANTSCH, A.; BIANCHETTI, L. Interdisciplinaridade, pesquisa e formação de trabalhadores: as interações entre o mundo do trabalho e da educação. In: JANTSCH, A.; BIANCHETTT, L. (Org.). Interdisciplinaridade: para além da filosofia do sujeito. Petrópolis: Vozes, 1995.

POMBO, O. Interdisciplinaridade e integração dos saberes. Liinc em Revista, v. 1, n. 1, p. 3-15, mar. 2004. Disponível em: <http://www.ibict.br/liinc>. Acesso em: 2 fev. 2015.

PORTO, M. F. de S.; ALMEIDA, G. E. S. de. Significados e limites das estratégias de integração disciplinar: uma reflexão sobre as contribuições da saúde do trabalhador. Ciência e Saúde coletiva, v. 7, n. 2, 2002. Pp.335-347. Disponível em: $\quad<$ http:/ / www.Scielosp.org/scielo.php?script=sciarttext\&pid=S1413812320 02000200013\&lng=pt\&nrm=iso > . Acesso em: 20 de fev. 2016.

UFBA. Universidade Federal da Bahia. Projeto Pedagógico dos Bacharelados Interdisciplinares. UFBA: Salvador, julho de 2008. Disponível em: https:// www.ufba.br/sites/devportal.ufba.br/files/implant_reuni.pdf. Acesso em: 15 de fev. 2016.

UFMA. Universidade Federal do Maranhão. Curso de Licenciatura Interdisciplinar em Ciências Humanas/História. Projeto PolíticoPedagógico. UFMA: São Luiz, 2013. Disponível em: http://www.ufma.br/ portalUFMA/arquivo/Gi1dwtZiVsbEKhE.pdf. Acesso em: 18 de janeiro, 2016.

UNIPAMPA. Universidade Federal do Pampa. Projeto de Graduação Licenciatura em Ciências Humanas. UNIPAMPA: São Borja, 2011. Disponível em: http://cursos.unipampa.edu.br/cursos/cienciashumanas/files/2012/02/ licenciatura-em-Ci\%C3\%AAncias-Humanas-04-10-20111.pdf. Acesso em: 18 de janeiro, 2016. 
ELIANA PÓVOAS PEREIRA ESTRELA BRITO é professora Associada da Universidade Federal do Sul da Bahia (UFSB). Graduada em Licenciatura em Pedagogia pela Fundação Universidade de Rio Grande - FURG/Rio Grande (1992), Especialista em Educação pelo Grupo de Estudos sobre Educação, Metodologia de Pesquisa e Ação - GEEMPA/RS (1993). Possui Mestrado e Doutorado em Educação pela Universidade Federal do Rio Grande do Sul UFRGS (2003).E-mail: epovoas@ufsb.edu.br

Recebido em setembro de 2016 Aprovado em novembro de 2016 